\title{
Optimization of process parameters during flow forming process and its verification
}

\author{
Ravi J. Bhatt*, Harit K. Raval** \\ *S V National Institute of Technology, Surat-395007, Gujarat, India, E-mail: d13me007@med.svnit.ac.in \\ **S V National Institute of Technology, Surat-395007, Gujarat, India, E-mail: hkr@med.svnit.ac.in \\ cross $^{\text {ref }}$ http://dx.doi.org/10.5755/j01.mech.23.4.15138
}

\section{Nomenclature}

$F_{x}$ - radial force, $\mathrm{N} ; F_{y}$ - circumferential force, $\mathrm{N} ; F_{z}$ - axial force, $\mathrm{N} ; f$ - feed, $\mathrm{mm} / \mathrm{s} ; R$ - roller radius, $\mathrm{mm} ; t_{i}$ - initial thickness of workpiece, $\mathrm{mm} ; \bar{\sigma}_{m}$ - effective yield stress, $\mathrm{MPa} ; \alpha$ - leading angle of roller, ${ }^{\circ}$

abbreviation -

DOF - degree of freedom; SS - sum square; MS - mean square.

\section{Introduction}

Flow forming is rotary contact forming process. In this process, a workpiece (normally axisymmetrical) is placed on the rigid mandrel and rotating rollers deformed the workpiece under the contact zone. Generally two strategies are employed during the process i.e. forward and backward. In forward process material deforms in the same direction of roller feed (Fig. 1) whereas in backward process the material deforms in opposite direction of roller feed (Fig. 2).

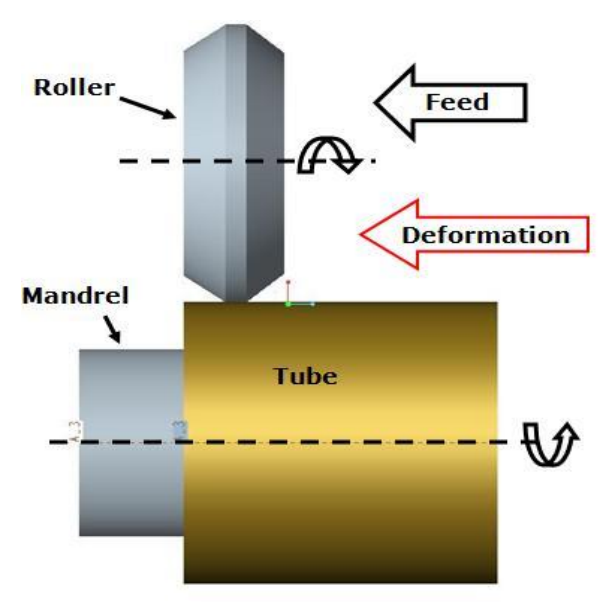

Fig. 1 Forward flow forming configuration

In the tube spinning the shear as well as compressive forces are applied on the tube/preform. The workpiece is deformed in the axial direction of motion. However internal diameter remains constant during the process. In flow forming, the blank is fitted onto the rotating mandrel and the rollers moves towards the blank in the axial direction and plasticise the metal under the contact point. In this way, the wall thickness changes results into increases in the length of the workpiece. Earlier, Srinivasulu et al. [1] had done experiments using single roller on CNC flowforming machine for AA6082. The experiments were per- formed to investigate effect of speed, feed and radius of roller on surface roughness using Box-Behnken design. Molladavoudi and Djavanroodi [2] had experimented flow forming machine using NC lathe machine. Wong et al. [3] have reported the relationship of roller configuration (flat roller \& nosed roller) with different feed rates on reduction rates during flow forming process. Taguchi approach was employed by Davidson et al. [4] for AA6061 and found that the spindle speed is the second most significant factor, affecting the flow forming process. Razani et al. [5] have done experimental study on AISI 304 stainless steel using RSM (Box-Behnken design) to analyze the effect of different leading angle on final hardness of the material.



Fig. 2 Backward flow forming configuration

Presently, finite element analysis based studies getting attentions by several research communities from last decade. The experimental work requires large quantity of tool and workpiece material thus it is a costly affair. Therefore, numerical based analysis is a good choice to reduce the experimentation without much loss of accuracy in the results. That ultimately reduces material and inventory carrying cost. Mohebbi et al. [6] had numerically investigated the straining pattern during process using ABAQUS. Kim et al. [7] had analyzed the different roller angles using upper bound method and simulations. Zoghi et al. [8] had done finite element analysis of hot tube necking process for $42 \mathrm{CrMo}$ steel. Xia et al. [9] had done the analysis of flow forming for non axisymmetrical geometry. Shinde et al. [10] had studied the effect of different parameters during three roller forward flow forming using facecentred central composite design (CCD) for Maraging steel.

In the present study, L9 Taguchi design has been used to study the effect of process parameters on the forces 
during flow forming process. A simulation model is developed \& rotational speed; axial feed and forming depth are considered as process parameters, which can be controlled manually during actual process. Three forces are acting during the process i.e. axial, radial and circumferential. These forces plays vital role while designing the tooling for forming of different material and geometrical conditions. This simulation model is verified by analytical model available in the literature [11].

\section{Analysis and Optimization}

\subsection{Analysis}

Flow forming is influenced by many factors viz. process parameters, geometry of the tool and material properties. In the present work process parameters are concentrated as it can be vary at will of the operator for uniform quality of product. There are basically three forces are encountered during the process axial, radial and circumferential. Figure 3 and 4 shows the initial 3D model with meshed blank and the forces acting during the process respectively.

In the present study, AA6063 used as the work material because of its light weight, ease of availability, cost effectiveness and versatile applications in aviation and defence sectors. The mechanical properties of AA 6063 are density $\rho=2700 \mathrm{~kg} / \mathrm{m}^{3}$, yield strength $=48.3 \mathrm{MPa}$, elastic modulas $=68.9 \mathrm{GPa}$, poisson's ratio $=0.33$, ultimate strength $=89.6 \mathrm{MPa}$ and the model configuration values are given in Table 1.

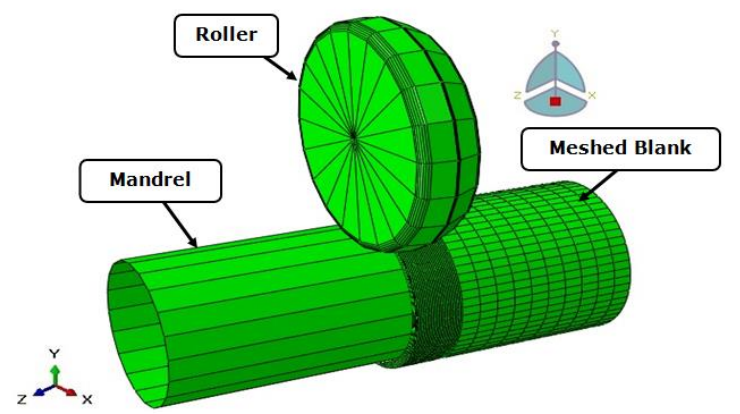

Fig. 3 Initial 3D model with meshed blank for backward strategy

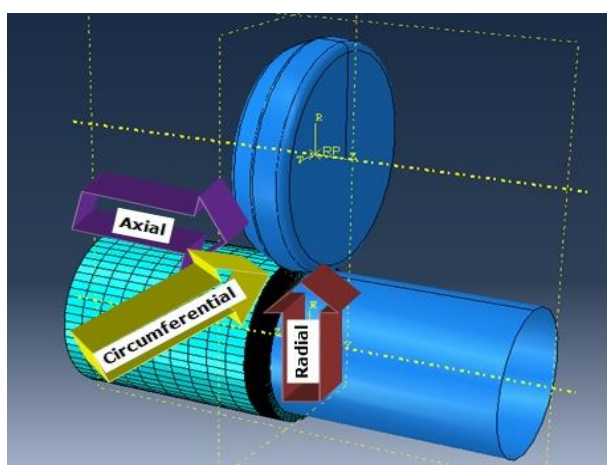

Fig. 4 Forces acting during process

Firstly, the analysis procedure has been benchmarked with the results of [6] and [7]. After successful benchmarking, subsequent analysis has been carried out during present study. The benchmarking is carried out con-
Table 1

Model configuration values [7]

\begin{tabular}{|c|c|}
\hline Parameter & Value \\
\hline Diameter of blank, mm & 35 \\
\hline Thickness of wall, mm & 2.5 \\
\hline Initial length of W/P, mm & 50 \\
\hline Diameter of roller, mm & 54 \\
\hline Roller attack angle, degree & 25 \\
\hline Relief angle of roller, degree & 5 \\
\hline Reduction percentage & 40 \\
\hline
\end{tabular}

sidering the same material, geometric, operating conditions and constraints of [6] (single roller forward strategy) and [7] (single roller backward strategy). Figs. 5 and 6 shows the comparison of results for variation of equivalent plastic strain and kinetic energy respectively. It can be seen that the nature of the curve is identical with [6] during first case of benchmarking. Further, the second case of benchmarking is carried out for the axial force encountered on the roller for different leading angles considering two different reduction rates proposed by [7]. It can be seen that good conformity found between both results (average values) as shown in Fig. 7 (20\% reduction) and Fig. 8 (40\% reduction).

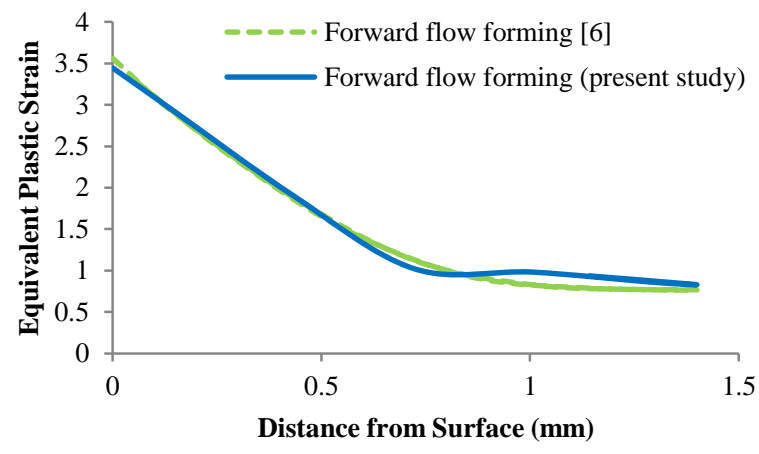

Fig. 5 Comparison of equivalent plastic strain along the surface

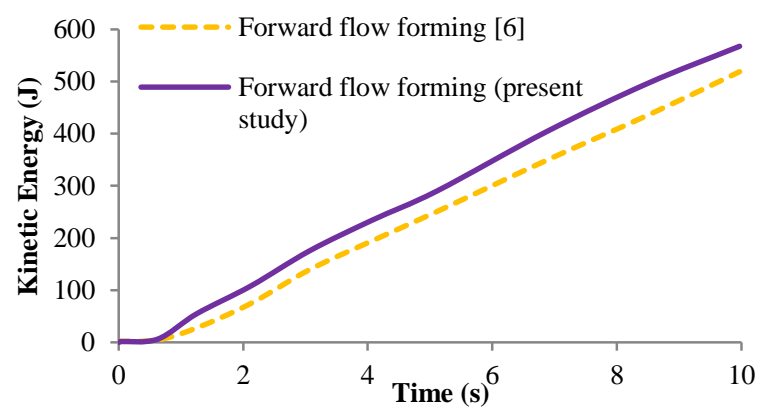

Fig. 6 Comparison of kinetic energy variations

Later, analysis is carried out to investigate effect of various operating variables. The loading and boundary conditions are applied based on the linear and rotary motions. 1) The workpiece is able to rotate with mandrel rotation. 2) Mandrel and roller are set to having opposite rotation. 3) Workpiece/blank is free to deform on one side (normally considered as tail stock side) and fixed at opposite end (normally considered as chuck side). 


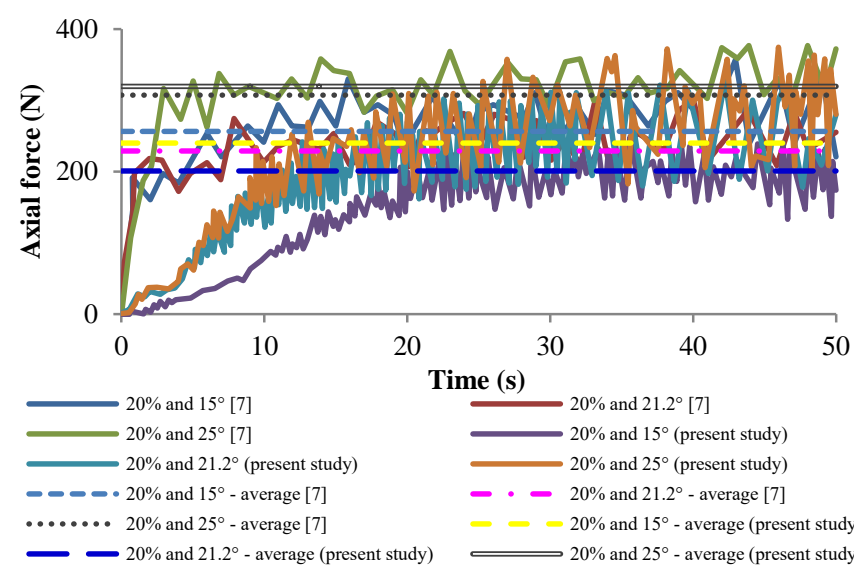

Fig. 7 Comparison of axial force for $20 \%$ reduction



Fig. 8 Comparison of axial force for $40 \%$ reduction

Also, roller and mandrel are taken as analytical rigid bodies (do not require meshing) which helps to reduce computational time and memory storage. The mesh sensitivity analysis is carried out based on the procedure proposed by [10] to decide optimum mesh size. The optimum mesh size is decided by taking several mesh size from 0.5 to $5 \mathrm{~mm}$ (in interval of $0.5 \mathrm{~mm}$ ). It was observed that finer mesh $(0.5 \mathrm{~mm})$ gives better results compared to courser mesh. The CPU time is slightly higher in fine mesh compared to course mesh. Further, adaptive meshing was employed in the forming area considering ALE (Arbitrary Lagrangian Eluerian) method to prevent severe mesh distortion during analysis. Dry friction has been considered between mandrel and workpiece $\left(\mu_{1}\right)$ and friction is taken as 0.2 between roller and blank $\left(\mu_{2}\right)$.

\subsection{Design of experiments}

In this section, simulations plan and procedure are described using design of experiment (DOE). In connection to this, Taguchi method is used because it is well established design of experiment technique which is normally used to analyze complex and expensive experiments. Identification and optimization of optimal combination of different factors on desired response can be done by this method. The process parameters for present study have been chosen as rotational speed (rotation of workpiece), axial feed (linear motion of roller during deformation) and forming depth (reduction given to the roller). The main reason behind these parameters selection is; these can be varied at operator will during actual processing. The values of these parameters are taken as forming depth (mm) 0.2 , 0.4 and 0.6; rotational speed (RPM) 30, 60 and 90; axial feed $(\mathrm{mm} / \mathrm{s}) \quad 0.05,0.10,0.15$. During the analysis, L9 design was used, which requires only nine simulations to be performed. These nine experiments are repeated twice followed by confirmation test. The simulation analysis layout is given in Table 2. After performing these simulations, the optimization of best combination is done using analysis of variance (ANOVA). It is done in order to identify significant process parameter.

Table 2

Simulation layout using L9 array

\begin{tabular}{|c|c|c|c|}
\hline \multirow{2}{*}{$\begin{array}{c}\text { Simulation } \\
\text { number }\end{array}$} & $\begin{array}{c}\text { Forming } \\
\text { depth, mm }\end{array}$ & $\begin{array}{c}\text { Rotational } \\
\text { speed, } \\
\text { RPM }\end{array}$ & $\begin{array}{c}\text { Axial } \\
\text { feed, mm/s }\end{array}$ \\
\hline 1 & 0.2 & 30 & 0.05 \\
\hline 2 & 0.2 & 60 & 0.10 \\
\hline 3 & 0.2 & 90 & 0.15 \\
\hline 4 & 0.4 & 30 & 0.10 \\
\hline 5 & 0.4 & 60 & 0.15 \\
\hline 6 & 0.4 & 90 & 0.05 \\
\hline 7 & 0.6 & 30 & 0.15 \\
\hline 8 & 0.6 & 60 & 0.05 \\
\hline 9 & 0.6 & 90 & 0.10 \\
\hline
\end{tabular}

\subsection{Analysis of results}

Taguchi [12] methodology depicts three types of quality characteristics i.e. smaller the better, nominal the better and larger the better. The calculations of signal to noise $(S / N)$ ratio are given in Eqs. (1), (2) and (3) for smaller the better, nominal the better and larger the better respectively [12]:

$$
S / N_{S B}=-10 \log \left(\sum_{i=1}^{r} y_{i}^{2}\right),
$$

where $r$ is number trials in an experiment, $y$ is observation.

$$
S / N_{N B}=-10 \log \left(\frac{\sum \bar{Y}^{2}}{s^{2}}\right),
$$

where $\bar{Y}$ is mean, $s$ is variance.

$$
S / N_{L B}=-10 \log \left(\frac{1}{r} \sum_{i=1}^{r} \frac{1}{y_{i}^{2}}\right),
$$

where $r$ is number trials in an experiment, $y$ is observation.

In the present study the forces should be minimal during the process. Hence smaller the better quality characteristic has used for $S / N$ (signal to noise) ratio calculation. Taguchi stated that higher $S / N$ ratio gives better performance. Therefore, better performance is the function of higher $S / N$ ratio. The main effect plot for mean of $S / N$ ratio for axial, radial and circumferential force is given in Fig. 9, Figs. 10 and 11 respectively. It can be seen from Fig. 9 that the optimal performance for the axial force can be achieved at forming depth $0.6 \mathrm{~mm}$ (level 3), rotational 
speed of $30 \mathrm{rpm}$ (level 1) and axial feed $0.05 \mathrm{~mm} / \mathrm{s}$ (level 1). Further it can be seen from Fig. 10 that the radial force optimal performance obtained at forming depth $0.6 \mathrm{~mm}$ (level 3), rotational speed 30 RPM (level 1) and axial feed $0.05 \mathrm{~mm} / \mathrm{s}$ (level 1). As can be seen from Fig. 11 that the optimal performance of circumferential force can be determined at $0.2 \mathrm{~mm}$ forming depth (level 1), $30 \mathrm{RPM}$ rotational speed (level 1) and $0.05 \mathrm{~mm} / \mathrm{s}$ axial feed (level 1). It can be noted that the 30 RPM rotational speed (level 1) and $0.05 \mathrm{~mm}$ axial feed (level 1) give best performance results for all the forces. It is obvious that smaller values of rotational speed and axial feed encounter smaller forces.

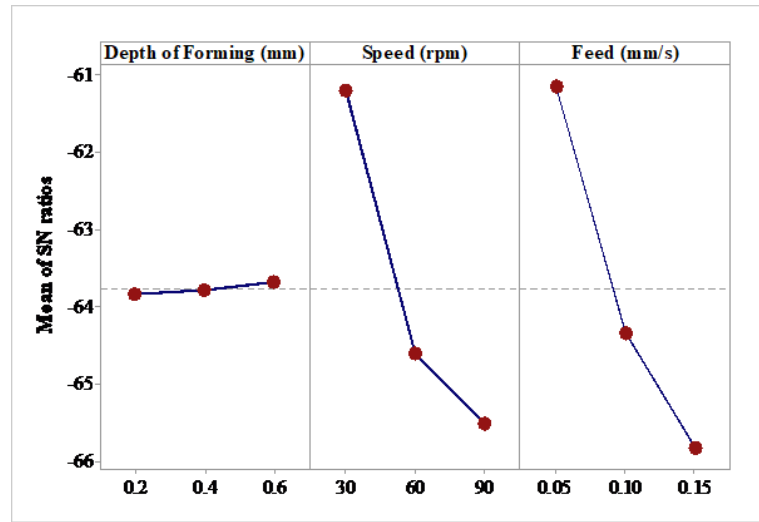

Fig. 9 Main effect plot for axial force

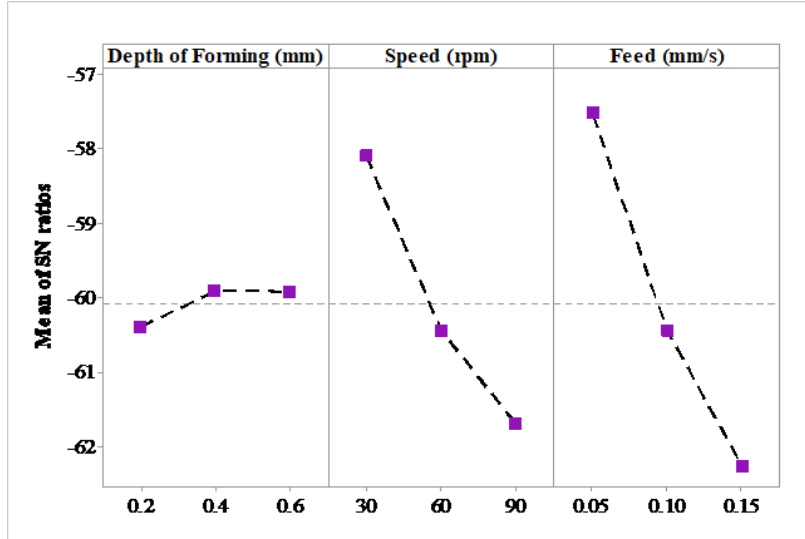

Fig. 10 Main effect plot for radial force

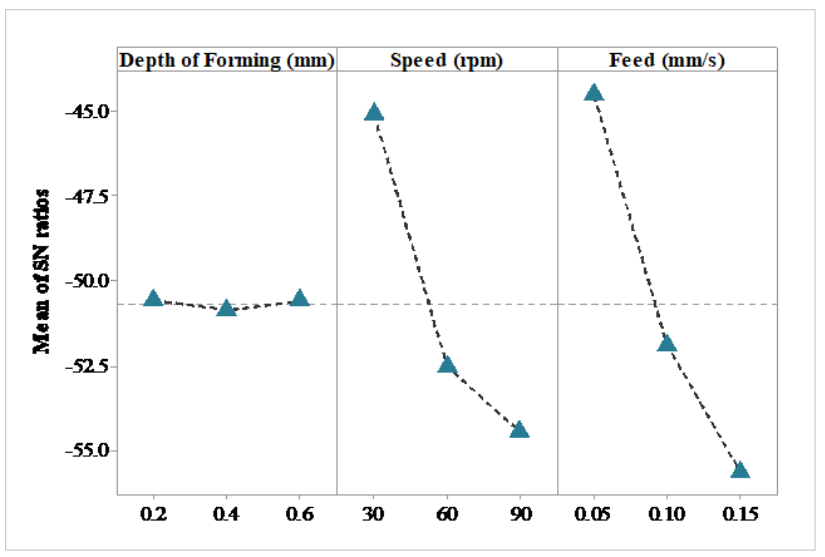

Fig. 11 Main effect plot for circumferential force

Further, the effect of operating parameters on elongation percentage is also studied. During the analysis a node has been selected and tracked in the deformation zone till completion of analysis, as shown in Fig. 12. The displacement of selected node is used in the calculation of percentage elongation using equation (4):

Elongation $\%=l_{1}-l_{0} / l_{0}$,

where $l_{0}$ and $l_{1}$ are initial and final length of workpiece respectively.

A sample of node displacement for simulation No. 1 is given in the Fig. 13. This gives the maximum displacement of the node, which is added in to the initial length of the work material to determine the final length. Here, larger the better quality characteristics used for percentage elongation. The main effect plot for $S / N$ ratio is given in Fig. 14. It shows that the optimum percentage elongation can be obtained at $0.6 \mathrm{~mm}$ depth of forming (level 3), 30 RPM rotational speed (level 1) and $0.10 \mathrm{~mm} / \mathrm{s}$ axial feed (level 2). Moreover, ANOVA has been performed to work out significant parameters which affect the performance characteristics.

During the ANOVA, the effect of contribution of individual parameter was considered. The P-value represents the statistical importance of each parameter. Here, the procedure of ANOVA is carried out based on the Taguchi et al [12]. Where in for the $95 \%$ confidence level the p-values of the statistically significant parameter should be less than 0.05 .

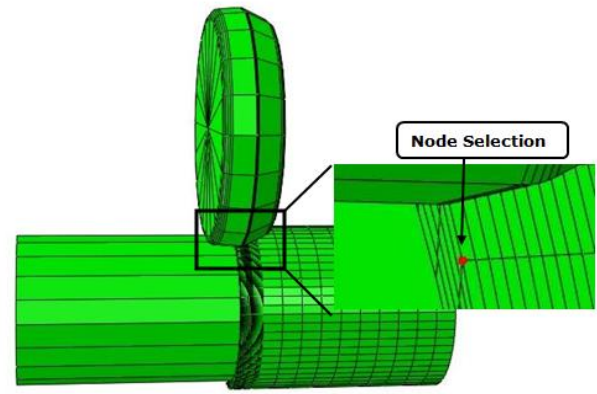

Fig. 12 Node Selection

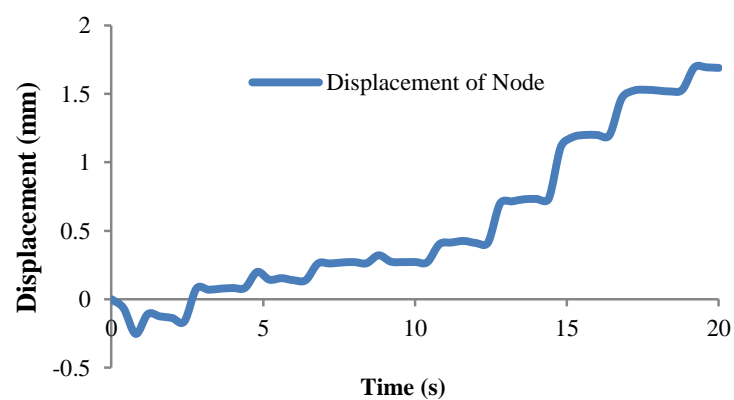

Fig. 13 Displacement of selected and tracked node

It can be observed from Table 3 (axial force) that speed and feed are having significant effect during the process based on $95 \%$ confidence level. The ANOVA summary for radial and circumferential force is given by Table 4 and 5 respectively. It is observed again that based on $95 \%$ confidence level speed and feed are found to be significant factors during the analysis. Table 6 shows ANOVA of percentage elongation. It can be said that none 
of the selected operating parameters are significant affecting the percentage elongation based on $\mathrm{P}$-value (for present set of data).

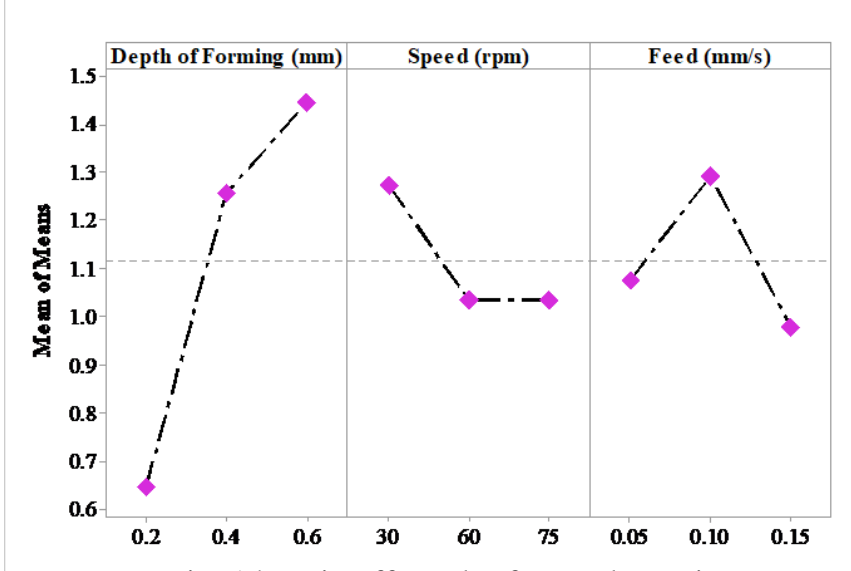

Fig. 14 Main effect plot for \% elongation

Table 3

ANOVA for axial force

\begin{tabular}{|c|c|c|c|c|c|}
\hline Factor & DOF & SS & MS & F & $\begin{array}{c}\text { P } \\
\text { value }\end{array}$ \\
\hline $\begin{array}{c}\text { Depth of } \\
\text { forming, } \\
\text { mm }\end{array}$ & 2 & 28056 & 14028 & 1.33 & 0.430 \\
\hline $\begin{array}{c}\text { Speed, } \\
\text { RPM }\end{array}$ & 2 & 932830 & 466415 & 44.14 & 0.022 \\
\hline $\begin{array}{c}\text { Feed, } \\
\mathrm{mm} / \mathrm{s}\end{array}$ & 2 & 1063267 & 531634 & 50.31 & 0.019 \\
\hline Error & 2 & 21134 & 10567 & - & - \\
\hline Total & 8 & 2045288 & - & - & - \\
\hline
\end{tabular}

ANOVA for radial force

Table 4

\begin{tabular}{|c|c|c|c|c|c|}
\hline Factor & DOF & SS & MS & F & $\begin{array}{c}\text { P } \\
\text { value }\end{array}$ \\
\hline $\begin{array}{c}\text { Depth of } \\
\text { forming, } \\
\text { mm }\end{array}$ & 2 & 0.4659 & 0.2330 & 0.99 & 0.503 \\
\hline $\begin{array}{c}\text { Speed, } \\
\text { RPM }\end{array}$ & 2 & 20.1007 & 10.0503 & 42.60 & 0.023 \\
\hline $\begin{array}{c}\text { Feed, } \\
\mathrm{mm} / \mathrm{s}\end{array}$ & 2 & 34.2263 & 17.1131 & 72.54 & 0.014 \\
\hline Error & 2 & 0.4718 & 0.2359 & - & - \\
\hline Total & 8 & 55.2647 & - & - & - \\
\hline
\end{tabular}

ANOVA for circumferential force

\begin{tabular}{|c|c|c|c|c|c|}
\hline Factor & DOF & SS & MS & F & $\begin{array}{c}\text { P } \\
\text { value }\end{array}$ \\
\hline $\begin{array}{c}\text { Depth of } \\
\text { forming, } \\
\text { mm }\end{array}$ & 2 & 0.151 & 0.0755 & 0.16 & 0.865 \\
\hline $\begin{array}{c}\text { Speed, } \\
\text { RPM }\end{array}$ & 2 & 147.015 & 73.5073 & 152.07 & 0.007 \\
\hline $\begin{array}{c}\text { Feed, } \\
\mathrm{mm} / \mathrm{s}\end{array}$ & 2 & 192.929 & 96.4643 & 199.56 & 0.005 \\
\hline Error & 2 & 0.967 & 0.4834 & - & - \\
\hline Total & 8 & 341.061 & - & - & - \\
\hline
\end{tabular}

Table 6

ANOVA for percentage elongation

\begin{tabular}{|c|c|c|c|c|c|}
\hline Factor & DOF & SS & MS & F & $\begin{array}{c}\text { P } \\
\text { value }\end{array}$ \\
\hline $\begin{array}{c}\text { Depth of } \\
\text { forming, } \\
\text { mm }\end{array}$ & 2 & 58.06 & 29.03 & 3.64 & 0.216 \\
\hline $\begin{array}{c}\text { Speed, } \\
\text { RPM }\end{array}$ & 2 & 28.57 & 14.284 & 1.79 & 0.359 \\
\hline $\begin{array}{c}\text { Feed, } \\
\mathrm{mm} / \mathrm{s}\end{array}$ & 2 & 11.75 & 5.873 & 0.74 & 0.576 \\
\hline Error & 2 & 15.97 & 7.986 & - & - \\
\hline Total & 8 & 114.35 & - & - & - \\
\hline
\end{tabular}

In present simulation model; Taguchi analysis and ANOVA is carried out to investigate effect of operating parameters on forces and elongation. It can be noticed that the rotational speed and axial feed are affecting the forces significantly compared to forming depth. Also, percentage elongation requires further study with other set of data (factors) in order to examine the effect of operating parameters on the elongation percentage.

\section{Verification}

In present study, a simulation model has been developed using Taguchi L9 design to optimize process parameters during flow forming. In connection to this, verification has been done using Thomson et al. [11] model. They had developed analytical model to estimate forces using slab and slip line methods. Equation (5) shows the relation of the forces proposed by Thomson et al. [11]:

$$
\frac{F_{x}}{\bar{\sigma}_{m}^{\prime} t_{i} f}=\frac{-F_{y}}{\bar{\sigma}_{m}^{\prime} t_{i} \sqrt{2 R f / \tan \alpha}}=\frac{F_{z}}{\bar{\sigma}_{m}^{\prime} t_{i} \sqrt{2 R f \tan \alpha}},
$$

here $\bar{\sigma}_{m}^{\prime}$ can be found as

$$
\bar{\sigma}_{m}^{\prime}=\frac{2}{\sqrt{3}} \bar{\sigma}_{m},
$$

where $F_{x}$ is radial force, $\mathrm{N} ; F_{y}$ is circumferential force, $\mathrm{N}$; $F_{z}$ is axial force, $\mathrm{N} ; f$ is feed, $\mathrm{mm} / \mathrm{rev} ; R$ is roller radius, $\mathrm{mm} ; t_{i}$ is initial thickness of workpiece, $\mathrm{mm} ; \alpha$ is leading angle of roller; $\bar{\sigma}_{m}$ is effective yield stress, MPa.

Based on the above Eq. (5), the verification of the simulation model is carried out. All the material as well as geometrical properties were kept same in order to maintain uniformity during analysis of both models.

Thomson et al. [11] proposed normalized force components as shown in Fig. 15, and according to that, these forces can be calculated theoretically. The graph represented in Fig. 15 shows the equilibrium condition of forces (Eq. 5) versus different reduction for various methods of analysis. It was also illustrated that drawing and extruding type are identical with forward and backward flow forming respectively. In present case, reduction percentage is taken as $40 \%$ (Table 1). Hence corresponding force component has been obtained from Fig. 15 for backward strategy using slab method curve. This force component is equated with Eq. (5) to resolve the forces analytically. 


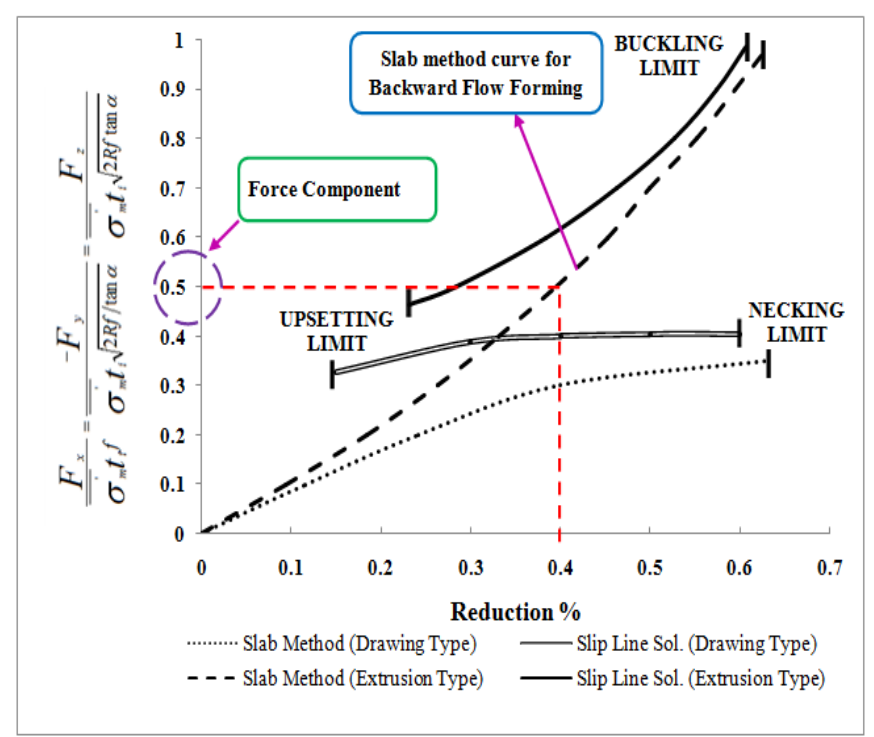

Fig. 15 Normalized force component selection using Thomson et al. Model (Redraw from [11])

The comparison of Thomson model with simulation model (Axial force Vs. Simulation run) is given in Fig. 16. It can be seen that maximum axial force value reaches up to $2500 \mathrm{~N}$ (approx.). The maximum value for radial force is obtained to be $1600 \mathrm{~N}$ (approx.) as shown in Fig. 17. While, circumferential force value found to be $900 \mathrm{~N}$ (approx.) as per Fig. 18. Thus axial fore is found to be highest, radial force is found to be second predominant and circumferential is least. It can be noticed that all the forces found to be higher for third simulation (i.e. $0.2 \mathrm{~mm}$ depth of forming, 90 RPM speed and $0.15 \mathrm{~mm} / \mathrm{s}$ feed) as shown in Fig. 19. It is because of higher values of rotational speed and axial feed for third simulation. As discussed earlier that forming depth is having lesser effect than rotational speed and axial feed. All the simulation run (for all the forces) found to be reasonably good agreement with the model proposed by Thomson et al. [11]. The maximum absolute error (average) for axial, radial and circumferential forces is found to be $2.8131 \%, 3.4082 \%$ and $4.5657 \%$ respectively between simulation model and analytical model. These variations are due to the certain assumptions like plain strain condition, strains in hoop direction are taken as zero and friction between tool and workpiece is negligibly small made in analytical model.

During the process of flow forming, material deformation is taking place axially due to shear and compressive deformation. It is mainly governed by depth of forming and axial feed of the roller. Hence axial force is found



Fig. 16 Comparison of axial force

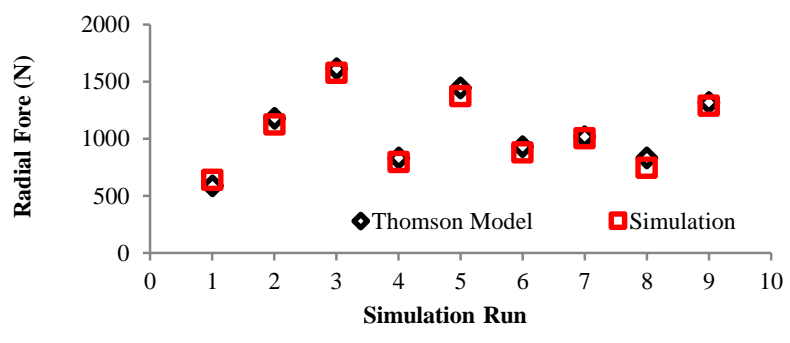

Fig. 17 Comparison of radial force

to be highest compared to other two forces. Further, radial force is due to depth of forming of the roller. It will deform the material radially. Therefore, radial force is found to be second dominant. Also because of roller and workpiece rotation, the instantaneous contact between roller and workpiece, generates circumferential force. The value of this force is quite less compared to other two forces due to rotary contact and rotary roller.

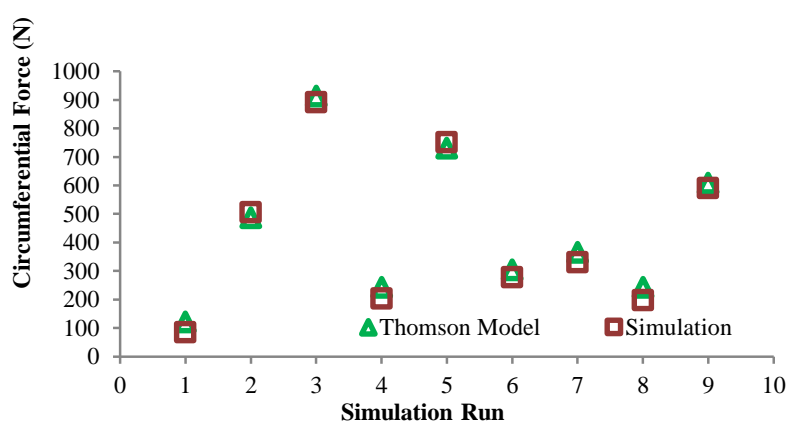

Fig. 18 Comparison of circumferential force

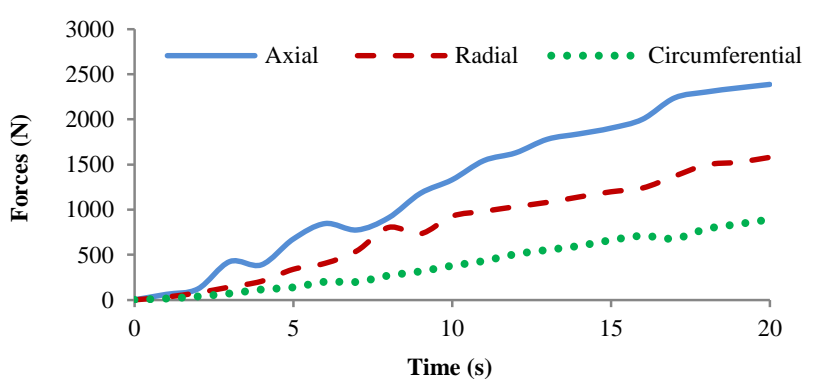

Fig. 19 Forces during third simulation run

\section{Conclusions}

In the present study, Taguchi L9 design used to develop simulation model in order to optimize process parameters during flow forming process. Also the simulation model is verified by the model proposed by Thomson et al. [11]. The summary of the major conclusions are given below.

- Rotational speed and axial feed are the most prominent factors during the process. It is noted that $30 \mathrm{RPM}$ speed and $0.05 \mathrm{~mm} / \mathrm{s}$ feed gives better results. Further, forming depth has little influence during the process.

- The percentage elongation has little effect of operating parameters. However, other data set of operating parameters can be used for further study.

- Axial force is found to be highest during all simulation runs followed by the radial and circumferential force respectively. As the material starts deforming (by depth and feed of roller) in axial direction, compressive and 
shear forces are increases thus raise the axial force significantly. Also, certain forming depth is provided, which will increases the compressive forces. Hence, radial force is second predominant. The roller and workpiece having instantaneous contact while forming due to angular motion of both. Therefore, small amount of contact took place during the process and that is the reason for very small amount of circumferential force compared to other two forces.

- Simulation model results are found in good agreement with the model proposed by Thomson et al. [11]. The maximum error between the Thomson model and simulation model found to be $2.8131 \%$ (axial force), $3.408 \%$ (radial force) and $4.5657 \%$ (circumferential force).

\section{Acknowledgement}

The authors are thankful to the directors and other technical staff of Paras Flowform Industry, Mumbai, India for providing in depth technical details and understanding about flow forming process.

\section{References}

1. Srinivasulu, M.; Komaraiah, M.; Krishna Prasada Rao, C. S. 2013. Prediction of the surface roughness of AA6082 flow-formed tubes by design of experiments, Journal of Mechanical Science and Technology 27 (6): 1835-1842. http://dx.doi.org/10.1007/s12206-013-0434-y.

2. Molladavoudi, H. R.; Djavanroodi, F. 2011. Experimental study of thickness reduction effects on mechanical properties and spinning accuracy of aluminum 7075-O, during flow forming, International Journal of Advance Manufacturing Technology 52: 949-957. http://dx.doi.org/ 10.1007/s00170-010-2782-4.

3. Wong, C. C.; Lin, J.; Dean, T. A. 2005. Effects of roller path and geometry on the flow forming of solid cylindrical components, Journal of Material Processing Technology 167: 344-353. http://dx.doi.org/ 10.1016/j.jmatprotec.2005.05.039.

4. Davidson, M. J.; Balasubramanian, K.; Tagore, G. R. N. 2008. Experimental investigation on flowforming of AA6061 alloy, Journal of Material Processing Technology 200: 321-325. http://dx.doi.org/10.1016/j.jmatprotec.2007.09.026.

5. Razani, N. A.; Agchai, A. J.; Dariani, B. M. 2014. Flow-forming optimization based on hardness of flowformed AISI321 tube using response surface method, International Journal of Advance Manufacturing Technology 70: 1463-1471. http://dx.doi.org/ 10.1007/s00170-013-5377-z.

6. Mohebbi, M. S.; Akbarzadeh, A. 2010. Experimental study and FEM analysis of redundant strains in flow forming of tubes, Journal of Materials Processing Technology 210 (2): 389-395. http://dx.doi.org/ 10.1016/j.jmatprotec.2009.09.028.

7. Kim, N.; Kim, H.; Jin, K. 2013. Minimizing the axial force and material build-up in the tube flow forming process, International Journal of Precision Engineering and Manufacturing 14 (2): 259-266. http://dx.doi.org/ 10.1007/s12541-013-0036-8.

8. Zoghi, H.; Arezoodar, A. F. 2013. Finite element study of stress and strain state during hot tube necking process, Proceedings of the Institution of Mechanical Engineers, Part B: Journal of Engineering Manufacture 227 (4): 551-564

http://dx.doi.org/ 10.1177/0954405413476495.

9. Xia, Q. X.; Cheng, X. Q.; Hu, Y.; Ruan, F. 2006. Finite element simulation and experimental investigation on the forming forces of 3D non-axisymmetrical tubes spinning, International Journal of Mechanical Sciences 48 (7): 726-735. http://dx.doi.org/ 10.1016/j.ijmecsci.2006.01.014.

10. Shinde, H.; Mahajan, P.; Singh, A. K.; Singh, R.; Narasimhan K. 2016. Process modeling and optimization of the staggered backward flow forming process of maraging steel via finite element simulations, The International Journal of Advanced Manufacturing Technology 87: 1851-1864. http://dx.doi.org/10.1007/s00170-016-8559-7.

11. Thomson, E. G.; Kobayashi, S.; Yang, C. T. 1965. Mechanics of plastic deformation in metal processing," First Ed. The Mac Millan Company, New York, USA, 396-476.

12. Taguchi, G.; Chowdhury, S.; Wu, Y. 2005 Taguchi's Quality Engineering Handbook, Second Ed. John Wiley and Sons, Inc., 145-379.

13. ABAQUS user manual, 2013.

Ravi J. Bhatt, Harit K. Raval

\section{OPTIMIZATION OF PROCESS PARAMETERS DURING FLOW FORMING PROCESS AND ITS VERIFICATION}

S u m m a r y

In present study; analysis, optimization and verification is carried out for flow forming process. Flow forming is plastic deformation process which used to manufacture high precision seamless components. The application of this process includes rocket missile casing, rocket motor case, vessels cartridge etc. in defence and aviation sector. Many experimental works have been done by several researchers but online monitoring of forces is still complicated in commercial machines. Force measurement and monitoring is important to design the tooling for different material and configurations of the product. Traditionally tooling design is done based on experience or hit and miss method. That increase lead time, material wastage and indirect cost. Hence a simulation model has been developed using Taguchi L9 design to study the effect of different operating variables like rotational speed, axial feed and forming depth on the forces (axial, radial and circumferential). Three levels of each parameter have been selected. It has been observed that the axial force is found to be highest followed by radial and circumferential during the analysis. Moreover the results have been verified with the analytical model proposed in the literature. The results have been found in good accordance.

Keywords: Flow Forming, Optimization, Process Parameters, Verification.

Received June 04, 2016

Accepted August 04, 2017 